\title{
A profile of sports hand injuries in an accident and emergency department
}

\author{
M Q Choyce, M Potts, A K Maitra
}

\begin{abstract}
Objective-To establish a profile of sports hand injuries requiring treatment in an urban accident and emergency (A\&E) department, and to determine the extent to which these injuries resulted in morbidity.

Methods-A one year prospective observational study at the Royal Victoria Infirmary, Newcastle upon Tyne. All patients presenting to the A\&E department between 29 July 1995 and 28 July 1996 with a hand injury sustained during sporting activity and who received follow up by $A \& E$ or plastic surgery units were enrolled. Patients were contacted by telephone or post at median of four months after injury (range two to 13) for their assessment of the outcome.
\end{abstract}

Results-262 cases were enrolled into the study. The median age for males was 21 years (range 7 to 55) and for females 16 (range 9 to 40). Follow up data were obtained by telephone in 206 (79\%), and by letter in a further $26(10 \%)$. Fractures were the commonest injury $(68 \%)$, followed by soft tissue injuries $(20 \%)$ and dislocations $(11 \%)$. The thumb was the site affected most commonly overall, and in 10 of 17 ski related injuries; next most frequent sites were little and ring fingers. Males sustained $79 \%$ of the injuries, and $54 \%$ of these occurred during football. Netball/basketball caused $63 \%$ of female injuries. Follow up indicated that mild impairment in terms of pain, stiffness, or deformity was common (45\%), while the incidence of moderate pain or serious problems was $11 \%$.

Conclusions-Sporting injuries to the hand commonly require treatment in the A\&E department. Telephone/postal follow up of such injuries indicates that significant short term and longer term impairment of function may result. Suitable target areas for injury prevention are secondary schools, football (in males), and netball/basketball.

(f Accid Emerg Med 1998;15:35-38)

Keywords: sports injury; hand injury; injury prevention; telephone survey

Sports injuries are a common problem in all parts of the developed world. An estimated 19 million injuries result in 1.3 million accident and emergency (A\&E) attendances annually in England and Wales. ${ }^{1}$ This is a cause of considerable morbidity and occasional fatality in young people, which therefore has significant economic implications ${ }^{2}{ }^{3}$; there is also a need for further work on the prevention of these injuries. ${ }^{4}$ No fundamentally different hand injuries occur in sport (with a few exceptions like rock climbing), ${ }^{5}$ reflecting the commonality of mechanisms in hand trauma. However, there is often a pattern of injuries specific to certain activities within particular sports, as shown for instance from the Finland national registry of injuries in six sports. ${ }^{6}$ This is subject to regional and national variation ${ }^{7}$ but the hand tends to be a common site of injury. In Newcastle, a preliminary search of the $A \& E$ department database indicated that about 5\% of new attendances were classified as sports injuries, and just under $20 \%$ of these involved the hand.

The first aim of this paper was to establish a profile of hand injuries arising during sport that presented to an urban $\mathrm{A} \& \mathrm{E}$ department and required further treatment. The second aim was to establish the degree of morbidity caused by these injuries. We then discuss how these data indicate areas with potential for preventing these injuries.

\section{Methods}

We studied a one year period to allow for seasonal variation. Our aim was to capture all sports related hand injuries that attended the $\mathrm{A} \& \mathrm{E}$ department at the Royal Victoria Infirmary, Newcastle upon Tyne, between 29 July 1995 and 28 July 1996 and were reviewed at least once in the department or were referred for review by the plastic surgery unit. We excluded those patients with injuries who were discharged to the care of their general practitioner or who did not attend their initial review appointment. This was in order to concentrate on the more serious injuries presenting during this period. This meant excluding patients with normal radiographs or who had wound closure if they were discharged from the A\&E department. We did not consider these latter groups as having injuries of sufficient severity to justify contacting them several months later to ascertain further information about their morbidity. We defined a hand injury as being distal to the carpo-metacarpal joints, excluding scaphoid and carpal injuries. We defined sports injuries as those sustained during any specified sporting activity, which we were able to confirm from hospital notes and directly with patients in the review clinic or by telephone.

A proforma was filled in by a middle grade or senior doctor at the review clinic. A search was also made of the computerised record 


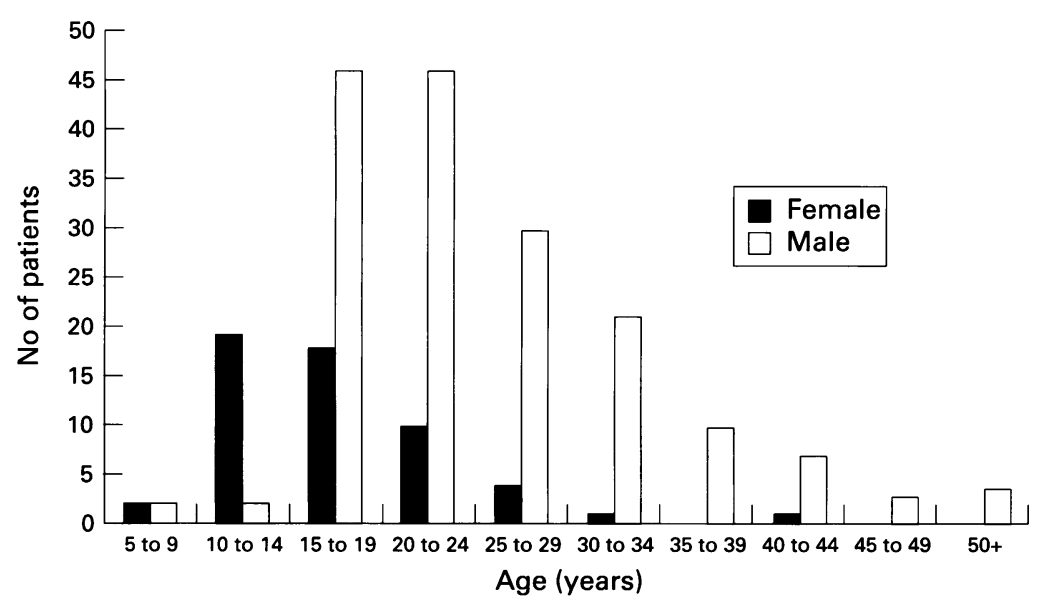

Figure 1 Age and sex of patients in study.

Table 1 Number (\%) of hand injuries caused by particular sports

\begin{tabular}{lccc}
\hline Sport & All cases $(n=262)$ & Males $(n=206)$ & Females $(n=56)$ \\
\hline Football & $114(43)$ & $112(54)$ & $2(4)$ \\
Basketball/netball & $47(18)$ & $12(6)$ & $35(63)$ \\
Rugby & $31(12)$ & $30(15)$ & $1(2)$ \\
Skiing etc $†$ & $17(7)$ & $14(7)$ & $3(5)$ \\
Hockey & $15(6)$ & $8(4)$ & $7(13)$ \\
Cricket & $14(5)$ & $14(7)$ & 0 \\
Boxing/gym/martial arts & $13(5)$ & $12(6)$ & $1(2)$ \\
Rounders/softball & $4(2)$ & $2(1)$ & $2(4)$ \\
Riding & $2(1)$ & 0 & $2(4)$ \\
Other & $4(2)$ & $2(1)$ & $2(4)$ \\
\hline
\end{tabular}

†Skiing, snowboarding, dry skiing, and toboganning.

$\ddagger$ Golf (one male), punchball (one male), outdoor bowls (one female), and water polo (one female).

linkage system to identify those remaining patients with sports hand injuries. The details noted were age, sex, occupation, handedness, contact address and/or telephone number, the side, site and nature of the injury sustained, the particular sport and the mechanism of injury, the treatment given, and a brief functional assessment on discharge. Patients were advised of the study and that we would aim to contact them at a later date for information about the further course of their injury.

The patients were contacted some months later for further information, when possible by telephone, otherwise by postal questionnaire. A semistructured approach to this telephone interview was used with an initial explanation or reminder as to the purpose of the call and verbal consent being sought from the patient, or a parent or responsible adult of those aged under 16. Details of the injury were confirmed, a brief functional assessment was obtained referring to pain, stiffness and deformity, and the time taken to return to work and sport was ascertained. Finally, we asked about changes in attitude to sport since the injury, and if any other problems had been encountered. The database was entered anonymously for analysis on Excel 7.0. $\chi^{2}$ Tests were performed using Minitab for Windows to evaluate statistical significance.

\section{Results}

The total number of patients was 262 . The male:female ratio was 3.8 to 1 ( $p<0.001)$. The median age was 20 years overall (range 7 to 55). The median age of the males was 21 years (range 7 to 55), and of the females, 16 (range 9 to 40) (fig 1); 149 patients were at school or students, 104 were professional or skilled workers, six were manual workers, and three were unemployed.

Fifty five patients $(21 \%)$ presented to the A\&E department within two hours of injury, $62(24 \%)$ between two and 12 hours, $66(25 \%)$ between 12 and 24 hours, and $76(29 \%)$ over 24 hours after injury.

In 150 of 254 cases (59\%) the activity was reported to be supervised. In 207 instances $(82 \%)$ the patient played the sport often, in 34 $(13 \%)$ the sport was not played often, and in $12(5 \%)$ it was the first experience of that sport.

\section{SPORTS RESPONSIBLE FOR INJURIES}

The types of sport resulting in injury to the hand are shown in table 1 . Football was the main cause of male injuries (54\%). This includes five-a-side football, and it emerged during the course of the study that a significant proportion of football injuries happened to goalkeepers (regular or occasional). Netball/ basketball $(63 \%)$ was the main source of injuries in females.

\section{INJURY DATA}

The 228 people who described themselves as right handed injured their right hand in 124 cases and their left hand in $104(\mathrm{p}>0.05)$. The 26 left handers sustained 19 injuries to their dominant hand and seven to their non-dominant right hand $(\mathrm{p}<0.02)$.

The thumb (including the first metacarpal) was the commonest site of injury $(27 \%)$, followed by little $(23 \%)$ and then ring $(15 \%)$ fingers, as shown in fig $2(\mathrm{p}<0.001)$. The adjacent table 2 also shows the regions of the hand at which injury occurred; the (distal) interphalangeal joint was affected significantly less frequently than other areas $(p<0.01)$. Ten of the 17 skiing related injuries affected the thumb, and the distribution of the thumb injuries was more proximal than in the other digits; these most frequently involved the metacarpo-

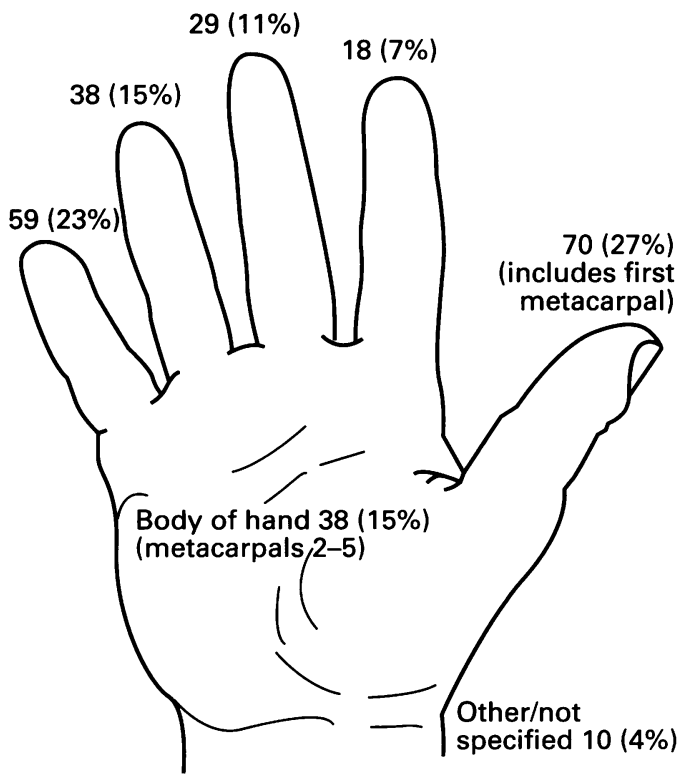

Figure 2 Distribution of sports hand injuries. 


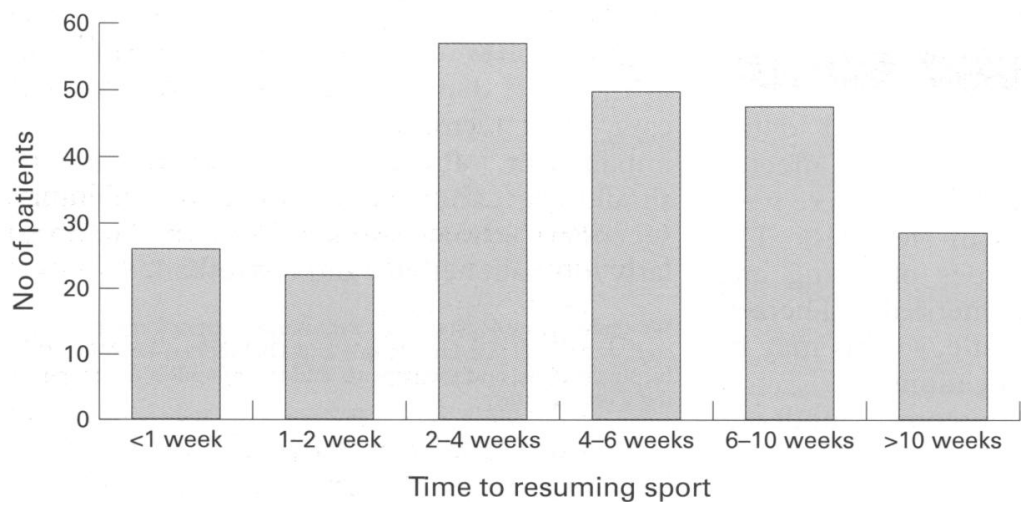

Figure 3 Times taken for patients in study to return to sport.

phalangeal joint (28 cases) and the proximal phalanx (14 cases).

Fractures were the commonest injury $(68 \%)$, with dislocations/fracture-dislocations at $11 \%$ and soft tissue injuries $20 \%$. Manipulation was performed for 45 cases $(17 \%)$ and surgery for $15(6 \%)$.

FOLLOW UP DATA

Follow up data were obtained by telephone in $206(79 \%)$ of the 262 cases, and by letter in a further $26(10 \%)$. This data were obtained at a median of four months after presentation; this time interval was the same for patients with and without morbidity. The success rate for receiving a reply to the postal questionnaire was $46 \%(26 / 56)$.

Eighty per cent of patients reported taking less than one week off work or school. The remaining $20 \%$ were off work or school for a period ranging from one to two weeks to over 10 weeks. Figure 3 shows how many weeks patients took to return to sporting activity. $67 \%$ took between two and ten weeks to

Table 2 Frequency of sites of injury for patients in the study

\begin{tabular}{ll}
\hline Region of injury & Number (\%) \\
\hline Metacarpals (all) & $50(19)$ \\
Metacarpo-phalangeal joints & $35(13)$ \\
Proximal phalanx & $42(16)$ \\
Proximal interphalangeal (I-P) joint & $37(14)$ \\
Middle phalanx & $54(21)$ \\
Distal I-P joint (includes thumb) & $11(4)$ \\
Distal phalanx & $23(9)$ \\
Other/not specified & $10(4)$ \\
\hline
\end{tabular}

Table 3 Number (\%) of study patients with problems with hand function

\begin{tabular}{|c|c|c|c|}
\hline \multirow[b]{2}{*}{ Criterion } & \multicolumn{3}{|l|}{ Status } \\
\hline & None & Mild & $\begin{array}{l}\text { Severe (includes } \\
\text { moderate pain) }\end{array}$ \\
\hline \multicolumn{4}{|c|}{ (A) At discharge from review } \\
\hline $\begin{array}{l}\text { Deformity } \\
(n=251)\end{array}$ & $167(67)$ & $77(31)$ & $7(3)$ \\
\hline $\begin{array}{l}\text { Pain } \\
(n=255)\end{array}$ & $138(54)$ & $107(42)$ & $7(3)$ \\
\hline $\begin{array}{l}\text { Stiffness } \\
(n=253)\end{array}$ & $161(64)$ & $87(34)$ & $5(2)$ \\
\hline \multicolumn{4}{|c|}{ (B) At follow up by telephone or post } \\
\hline $\begin{array}{l}\text { Deformity } \\
(n=232)\end{array}$ & $147(63)$ & $75(32)$ & $10(4)$ \\
\hline $\begin{array}{l}\text { Pain } \\
(n=227)\end{array}$ & $157(69)$ & $54(24)$ & $16(7)$ \\
\hline $\begin{array}{l}\text { Stiffness } \\
(n=231)\end{array}$ & $168(73)$ & $57(25)$ & $6(3)$ \\
\hline
\end{tabular}

resume sport but $13 \%$ had not done so after more than ten weeks. Only one patient could be identified who admitted returning to sport before resuming work. In more open questions about other problems, some (generally older) patients commented that they had changed the way they played their sport, changed sports or given up altogether. This seemed to be due to a perception that they could not risk another injury and incur more time off work.

Follow up indicated the degree of impairment in three areas: deformity, pain, and stiffness (table 3 ); 102 cases $(44 \%)$ reported none of these problems, 105 (45\%) reported one or more mild problems, while the combined incidence of moderate pain (10 cases) or at least one severe problem (15 cases) was $11 \%$.

\section{Discussion}

PATTERNS OF INJURY

This study is hospital based and generally only a minority of patients with sports injuries will seek treatment from the $\mathrm{A} \& \mathrm{E}$ department. ${ }^{2}{ }^{8}$ If treatment is sought it may be from a general practitioner or a sports injury clinic. Our results apply only to hand injury in one area of England. It is nevertheless important to ask whether there is likely to be morbidity in the local population arising from sporting hand injuries that have not been treated in the $A \& E$ department. There may also be additional morbidity that we did not look for in those patients seen once in the $A \& E$ department and discharged. One retrospective study of 226 volleyball hand injuries that had presented to a Dutch trauma department used a telephone interview at a mean of five years later and showed a prevalence of ongoing morbidity of $28 \%$.

AGE AND SEX DIFFERENCES

There are considerable differences in this study between the sexes regarding the actual sports that resulted in injury. Also, injured females were younger than males. In the 102 children (up to and including 16 years old) the male:female ratio was $2: 1$; in those aged 17 and over this ratio was $6.6: 1$. The high overall proportion of males injured has been found previously in many settings. One review of soccer injuries identified three risk factors: being male, playing competitive sport, and playing to a high standard. ${ }^{10}$ A study of hockey injuries ${ }^{11}$ indicated that the males had an average of 1.0 injury per season, while females had an average of only 0.6. Do women exercise less, differently, or more sensibly?

Without information about the local population's pattern of sporting activity, no firm conclusions can be drawn about the relative rates of hand injury in various sports. In Britain, available data indicate that rugby, cricket, and the martial arts are associated with the highest overall injury rates. ${ }^{2}{ }^{12}$ It would be valuable to know the percentage in north east England of soccer, rugby, and cricket played by females, as these are the sports in which male injuries are most predominant. A self completion questionnaire administered to 
over 5000 11-14 year old Newcastle schoolchildren indicated that boys were 7.5 times more likely than girls to play football at least weekly (Towner EML, unpublished data). While $98 \%$ of the football injuries affected males, in those aged 16 and below there were 33 in males and two in females. The association between all types of skiing and thumb injury is well documented. ${ }^{13}$ There is no dry ski slope in Newcastle, so this may be more significant in other locations.

Patients with a poor outcome (moderate pain and/or severe problems) were older than the average in this study: median 24 years, range 13 to 42 . The similarity between levels of impairment at discharge and at subsequent follow up has a clinical implication: patients with poor function after a hand injury should not be discharged from review in the expectation that they will improve with time.

\section{STRATEGIES FOR INJURY PREVENTION}

Further collaborative work is in progress to disseminate these results to local injury prevention agencies. We aim to raise local awareness in sports teachers, particularly in secondary schools; this was the setting for an effective campaign to reduce dental injuries in rugby players in New Zealand. ${ }^{14}$ Secondary schools in Newcastle ${ }^{15}{ }^{16}$ and in general ${ }^{17}$ appear to be a common location for both sports and nonsports injury. The pupils are mainly supervised during school activities; teachers and parents are in a position to educate children, influence the way sport is played, and enforce environmental modifications such as the introduction of protective equipment. By raising awareness of our findings we hope to reduce hand injuries and help sports workers ensure that the right people are playing the right sport in the right environment.
CONCLUSIONS

Sports injuries to the hand requiring treatment in the $A \& E$ department may result in significant short term and longer term functional impairment. Prevention of these injuries should be addressed locally by targeting secondary schools and specific sports, particularly football, netball, and basketball.

We thank Clare Richards for secretarial support, middle grade staff at the RVI, Dr Jane Noble and Dr Stephen Lord for helpful suggestions, and the patients and their families for cooperating with the study.

1 Campbell H, Stone D. Preventing sports and leisure injuries. BMJ 1996;313:182-3.

2 Tonks A. Costs of sports injuries may be justified. BMJ 1993;306:1148.

3 Barker M, Power C, Roberts I. Injuries and the risk of disability in teenagers and young adults. Arch Dis Child disability in teen

4 Nuffield Institute for Health, University of Leeds, NHS Centre for Reviews and Dissemination, University of York. Preventing unintentional injuries in children and young adolescents. Effective Health Care 1996;2:1-16.

5 Rooks MD, Johnston RB, Ensor CD, McIntosh B, James S. Injury patterns in recreational rock climbers. Am J Sports Med 1995;23:683-5.

6 Kujala UM, Tamela S, Antti-Poika I, Prava S, Tuominen R, Myllynen P. Acute injuries in soccer, ice hockey, volleyball, basketball, judo and karate: analysis of national registry data. BMJ 1995;311:1465-8.

7 Cuddihy B, Hurley M. Contact sports and injury. Irish Med J 1990;83:98-100.

8 Nicholl N, Coleman P. Acute sports injuries [letter]. BMJ 1996;312:844.

9 Bhairo NH, Nijsten MWN, van Dalen KC, ten Duis H-J. Hand injuries in volleyball. Int J Sports Med 1992;13: Hand 4 .

10 Inklaar $H$. Soccer injuries. I: Incidence and severity. Sports Med 1994;18:55-73.

11 Eggers-Stroder G, Hermann B. Injuries in field hockey. Sportverletzung Sportschaden 1994;8:93-7.

12 Department of Trade and Industry. Home and leisure acciden research: 1991. London: Consumer Safety Unit, DTI, 1993

13 Pechlaner S, Suckert K, Sailer R. Hand injuries in Alpine skiing. Sportverletzung Sportschaden 1987;1:171-6.

14 Morton JG, Burton JF. An evaluation of the effectiveness of mouthguards in high-school rugby players. NZ Dental J 1979;75:151-3.

15 Maitra AK, Sweeney G. Are schools safer for children than public places? J Accid Emerg Med 1996;13:196-7.

16 Maitra AK. School accidents to children: time to act. J Accid Emerg Med 1997;14:240-2.

17 Laflamme L, Menckel E. School injuries in an occupational health perspective: what do we learn from community based epidemiological studies? Injury Prevention 1997;3: 50-6.

The next Diet of the Faculty's Exit Examination will be on 6/7 May 1998 at the University of Edinburgh.

Inquiries to the Faculty of Accident and Emergency Medicine, 35-43 Lincoln's Inn Fields, London WC2A 3PN; tel +44 (0)171 4057071. 